Mäetagused 132000

\title{
Tõrjemaagiast matusekommetes
}

\section{$\underline{\text { Eha Viluoja }}$}

Inimese surma ja matustega on rahvatraditsioonis kaasnenud käitumisjuhised (käsud ja keelud) ning tõrjemaagilised toimingud, mille eesmärgiks on olnud: 1) surma kui nähtuse eemaldamine antud kohast, 2) surnu kahjuliku mõju vältimine/neutraliseerimine ja majandustulu säilitamine, 3) kurjade jõudude tõrje seoses laiba kaitsmisega ning 4) surnu kodukäimise vältimine või lõpetamine. Käesolevas kirjutises pööratakse peatähelepanu viimatinimetatule. Muueesmärgilisele tõrjele viidatakse vaid siis, kui see langeb ühte või satub vastuollu kodukäijatõrjega. Alati aga ei selgugi, mida on konkreetse tõrjemenetlusega taotletud.

Eestlastel nagu teistelgi rahvastel on olnud kindlad rituaalsed reeglid elavate suhtlemiseks surnutega. Surnud esivanemad olid oodatud külalisteks kodudes hingedeajal $\underline{1}$ - paikkonniti erineval ajavahemikul mihklipäeva (29. IX) ja jõulude vahel. Setudel oli surnu kodupiiris liikumise aeg individuaalne: kuus nädalat pärast surma. Surnu oletatavat kojutulekut väljaspool traditsioonis ettenähtud aega peeti ebanormaalseks, seda püüti vältida ja lõpetada. Niisugust tagasipöörduvat surnut nimetati kodukäijaks. Oskar Looritsa väitel on eestlased pööranud kodukäija tõrjele suhteliselt palju tähelepanu (Loorits 1927; 1949).

Kodukäimise põhjused usuti peituvat surnus endas või olukordades ja teistes inimestes, kes surnut kas tema eluajal või pärast surma on vääralt kohelnud. Kodukäijad võib rühmitada kolme gruppi: süüdlased, süütud, muud (Simonsuuri 1961: 53-55). Süütuid kodukäijaid on omakorda jaotatud muretsejateks, kättemaksjateks ja rahulolematuteks (Pentikäinen 1968: 54). Nn süütut kodukäimist arvati tingituks muuhulgas lahkunu viimase tahte eiramisest ja matuste käigus tehtud vigadest (vrd Lehto 1982: I). Kodukäimise vältimiseks oli seega oluline matuste kui siirderituaali traditsioonikohane läbiviimine.

Siirderiituse teooriale aluse pannud Arnold van Gennep jaotas siirderiitused kolme rühma: lahutamis-, ülemineku- ja liitmisriitused. $\underline{\underline{2}}$ Seejuures tuleb silmas pidada, et siirderiituste omavaheline järjestus ei ole ajas ühene (Honko 1964: 121-122). Sama funktsiooniga riitused esinevad rituaali eri etappidel, paigutudes teiste riituste suhtes mitmeti. Matuste puhul näiteks võivad sama eesmärgiga riitused leida aset kodus enne matmist, kalmistuteel, kalmistul, tagasiteel ja kodus pärast matmist. Surija ja surnuga seotud ning (täielikult või osaliselt) surma ja kodukäimise vältimisele suunatud toimingud võiks paigutada van Gennepi siirderiituste skeemile üldjoontes alljärgnevalt. ${ }^{3}$ Lahutamisriitused, s.t kontakti lõpetamine surnu ja tema eelmise keskkonna vahel: uste ja akende avamine suremise ajal, et hing saaks lahkuda (ERA II 282, 386/7 (34) < Trv); surnu suu ja silmade sulgemine; peegeldavate pindade katmine, $\underline{\mathbf{5}}$ et surnu vaim ei jääks neisse; kummuli anumate ümberpööramine, et surnu vaim ei jääks sinna alla (E $64433(15)<\mathrm{Ksi}$ ); surnu asend kodus - jalad ukse poole, kalmistule viimisel - jalad ees; surnukeha pesemine; nõiaks peetu surnukeha hoidmine eluhoonest põhja pool (H IV 7, 49 (34) < Jür); $\underline{\mathbf{6}}$ kirstualuste või kõikide pinkide ümberlükkamine surnu väljakandmisel (RKM II 3, 90 (30) < Kär; RKM II 3, 94/5 (47) < Kär); hoolitsemine, et kirst ei puutuks väljakandmisel uksepiita ega seinu (VMr, Vil, Ksi, Pal, Äks, Räp); keeld teha ristile talumärk kodus (H II 9, $65(20)<$ VNg); puhastusriitused: ${ }^{7}$ surnuga seotud ainete ja esemete hävitamine, kodust eemaldamine või puhastamine (surnupesuvesi, surnu all olnud õled, surivoodi, suririided, lautsi, kirstu tegemisel järelejäänud laastud $\underline{8}$ ja lauajupid, $\underline{\mathbf{9}}$ puusärgimõõ) $; \underline{\mathbf{1 0}}$ kodumaja (maagiline) puhastamine (põrandate pühkimine; ruumide suitsutamine kadakaokstega; harukordse toiminguna niidi põletamine surivoodist kuni kohani, kus lahku- 
nu viimati käis (ERA II 159, 500 (58) < Mar); surnu peast võetud juuste põletamine (H II 28, $55(61)<\ddot{A k s}) ; \underline{11}$ õue pühkimine sealt, kust surnu üle viidi (E $269 / 70<$ Jõh); ;2 pühkmete, tuha ja süte surnule järeleheitmine (Eisen 1897; Loorits 1949: 81);무 matuseliste rituaalne puhastamine (läbi tule sõitmine tagasiteel, käte pesemine pärast kojujõudmist, aga võib-olla ka käe/kätega ahju puudutamine ${ }^{\mathbf{1 4}}$ ); matuseliste kontakti katkestamine lahkunu ja surnuaiaga (kihutamine kalmistult naasmisel; $\stackrel{15}{\text { 15 }}$ labida mahaviskamine matmast tulles (H II 46, 418 (7) < Hlj)). Kontakti lõpetamist kindlustati piiri seadmisega elavate ja surnu vahele, aga sellest pikemalt 4. tõrjerühmas.

Üleminekuriitustesse kuulub surija ja surnu kaitsmine ${ }^{\mathbf{1 6}}$ kurjade jõudude eest: valvamine surija $\underline{17}$ ja surnu juures; tule (küünla) põletamine surnu juures; risti, pühakirja või lauluraamatu asetamine surnu rinnale; leivalabida panemine lae vahele puusärgi päitsi kohale surnu kirstupaneku ajaks (E 29890 (4) < Krk; H II 42, 819 (4) < Krk). ${ }^{18}$ Enesestmõistetavalt kuulub siia ka surnu tavakohane siirdamine ruumis - viimine kodust matmispaika.

Ühendamisriituste käigus varustatakse surnu teispoolseks eksistentsiks vajalikuks peetuga (traditsiooniline surnuriietus, mõningate esemete, nagu surnupesemiseviht, peahari, (hõbe)raha, mõni tööriist või lemmikasi, aga ka eluajal väljakammitud juuste (KKI 65, 410/1 $(10)<\mathrm{Kad}$ ), äralõigatud küünte ja väljalangenud hammaste (Loorits 1948: 20-21)ำ kaasapanek). Siia kuulub ka otsene või sümboolne ohverdamine: matusteks mingi looma tapmine selgi juhul, kui liha on külluses, samuti kerjustele annetamine, aga võib-olla ka mõnede ainete, nagu muld/liiv (setudel) ja õlu (saarlastel) järeleheitmine surnule. $\underline{\mathbf{2 0}}$ Reegli rikkumine võib põhjustada uskumust mööda nii surnu kodukäimist kui ka majanduslikku kahju (loomade surm).

Seal, kus itkutraditsioon on veel tuntud nagu setudel, saadavad siirderituaali itkud, milles piiritletakse, millal ja kuidas võib surnu astuda kontakti elavatega, endise keskkonnaga.

Niisiis on osa tavasid matusekombestiku komponendina kohaldatavad kõigi surnute puhul. Nende täitmata jätmise (üheks) sanktsiooniks on kodukäimine. Spetsiifiliselt tõrjeiseloomuga vahendid leiavad kasutamist üksnes eriti kardetud surnute puhul või alles siis, kui kodukäimine on kogejate meelest juba ilmnenud. Muistendites võib surnu ilmutada aktiivsust juba surma ja matmise vahelisel perioodil või siis matjate naasmisel kalmistult peietele. Kodukäimise lõpetamiseks on veel rida eriabinõusid, mis aga pole vaadeldavad käesoleva teema raames.

Ei olegi nii lihtne anda kõikehõlmavat ühelt aluselt tehtud klassifikatsiooni kodukäimise vältimis- ja tõrjeviisidest. Üheks võimaluseks on liigitada need funktsionaalseteks rühmadeks.

1. Kontakti lõpetamine surnu ja tema endise keskkonna vahel, millest oli juba eespool juttu seoses lahutamisriitustega.

2. Surnu liikumisvõime piiramine või kaotamine. Tingimisi tahaks siinkohal peatuda surnu erilisel riietamisel. Nimelt võidi surnule, selleks et ta koju ei tuleks, mõned rõivad - särk (ERA II 125, 110/1 < Iis < VNg; ERA II 125, 220 (52) < Jõh < Iis) või kindad (H III 17, 397 (67) < VMr < Kad; RKM II 2, 100 (72) < Khk) - pahempidi selga või kätte panna. ${ }^{21}$ Kui eelneva toimingu puhul jääb hüpoteetiliseks, miks see kodukäimist takistama peaks, siis järgnevad võtted - meessurnutel püksisäärte kokkuõmblemine (ERA II 125, 110/1 < Iis < VNg; ERA II 125, 220 (52) < Jõh < Iis) ja surnu lina sisse õmblemine (ERM 166, $11(36)<$ Emm) - on ühemõttelised. $\underline{22}$ 
On teade surnu silmade sidumisest musta rätiga, mille sõlmede kohta on tehtud ristid $($ E $54447<$ Jõe = ERM 165, $27 / 9$ (83) < Jõe = ERM 165, 29 (85) < Jõe).

Hoopis levinum oli surnu käte ja jalgade sidumine, enim teateid on Põhja- ja KirdeEestist. Sidumisvahendina on kasutatud enamasti musta või punast villast lõnga, nimetatud on ka siidniiti, vokinööri, sitsirätikut, piimapüti vitsu, pihlakavääti ja niinekammitsaid. Sidumisviise on mitmesuguseid, alates lõnga sümboolsest kinnitamisest jäsemete (Eisen 1897: 50) või ka ainult vasaku jala suure varba külge (E 80210 (2) < $\mathrm{VMr}$ ) kuni jalgade (harvem käte) kokkusidumiseni erineval kombel (nt suurte varvaste kokkusidumine, jalgade kokkusidumine pealtpoolt põlvi või kolmest kohast, jalgade risti sidumine, kaela ja pahema jala ühendamine köie abil). Sidumisvahend võis olla kolmekordne või seotud kolm korda ümber jäsemete. On teada ka viie lõngaga kammitsemisest (E, StK 34, 197 (32) < Ksi < Kod). Tähtsust omistati sõlmede arvule (3, 9), paiknemisele ja tegemisviisile. Jääb mulje, et jäsemed seoti kinni põhiliselt - või ka ainult - neil surnutel, kellest kardeti kodukäimist. $\underline{23}$ Andmed kombe kohta on pärit nii uskumusteadetest kui ka memoraatidest ja muistenditest.

Ohtlikuks peetud surnute (nõiad, halvad inimesed) puhul on äärmusliku abinõuna kodukäimise vältimiseks kasutatud surnukeha vigastamist. Sümboolse vigastamisena võib käsitada surnu varvaste (H II 64, 162 (12) < Vas; ERA II 138, 58 (72) < Trt < Har) või jala (H II 38, 850 (1) < Pde < Ta) muljumist. $\underline{24}$ Uskumusteadetes räägitakse surnu jalataldade torkimisest nõelaga (E 37953 (i) < Kad) ja kolme nõela panemisest surnu taldade alla (H II 46, $647(236)<\mathrm{Kad})$ tema püstitõusmise takistuseks. Ka pihlakapulgad surnu jalgade all pidid kodukäimise ära hoidma (ERA II 166, 183 (59) < Jõh). $\underline{25}$

Terves reas muistendites on juttu surnust, kes käib kodus, kirstutükk jala või lauba küljes. Siin võib põhjusi olla kaks. Nimelt on ühe uskumusteate (H III 12, 385 (3) < VMr) ja ühe muistendi (ERA II 19, 190 (25) < Kos) kohaselt löödud nael läbi kirstu põhjalaua surnu jalga takistamaks kodukäimist. $\underline{26}$ Usutav on ka mõttekäik, et kogemata surnukehasse löödud nael just põhjustaski kodukäimise.

3. Surnu eksitamine. Sel eesmärgil pühiti või rehitseti matuseliste jäljed koduõuel, teel, mida mööda surnuga mindi (E 269 (10) < Jõh; KKI 38, 344 (20) < Koe; Amb (Eisen 1897: 51); HJn (Loorits 1949: 82)), või haua ümber (ERM 164, $27(1)<\mathrm{MMg}) . \stackrel{\mathbf{2 7}}{\text { Ainulaadses }}$ teates väidetakse mõisnikutütreid oma isa matuserongis kudunuvat jälgede segamiseks (ERA II 70, $163(11)<\mathrm{Khn})$.

Kuna usuti, et surnu tuleb tagasi sama teed pidi, mida mööda ta surnuaeda viidi, siis oli üheks ettevaatusabinõuks matmispaigale minek keerulisi ja tundmatuid teid pidi (Loorits 1949: 82). Räägitud on ka surnu viimisest erandkorras üle põllu, $\stackrel{28}{2}$ mis üldiselt oli keelatud, kuna surnule omistati saaki kahjustavat mõju (Loorits 1949: 82). ${ }^{29}$ Läbi vee sõitmist võib mõista nii jälgede kaotamise (H II 49, 732/3 (60) < Plt; ERA II 274, 637/8 (53) < Räp; ERA II 274, 641/2 (60) < Räp) kui ka tõkke seadmisena - surnu ei saa üle jõe (vt 4. tõrjerühm). 
Teisal sõideti surnuga kalmistule suurt teed mööda, tagasi aga salateitsi, et lahkunu ei oskaks järgneda (KKI, MT 19, 63 ja $76<$ Se).

On teateid surnu väljaviimisest värava kõrvalt, hoidmaks ära tema koju tagasitulekut (E $48088(12)<$ Trm, Avi; ERA II 215, 603 (16) < Lüg). $\underline{\mathbf{3 0}}$

Surnu orienteerumisvõime kaotamiseks ... Enne toast välja viimist keeratud puusärk kord ringi, vastu päeva (RKM II 121, 249 (9) < VMr) või ... tuleb suurel teel, ristteel, kui surnu viiakse, keerata puusärgiga kolm korda vastu päeva. ... Kui kodukäija tuleb sinna kohta, siis käib kolm korda ringi ja eksib ära ning läheb surnuaiale tagasi... (ERA II 1, $692(15)<$ Rei). $\underline{31}$

Samal eesmärgil käidi või sõideti kirstuga ümber õue (H IV 7, 49 (34) < Jür; RKM II 3, 90 (303) < Kär) või mingi objekti, nagu leinamaja (H II 17, 271 (49) < VMr; KKI, 107 (8) $<$ Mus = KKI 11, 304 (3) < Mus), teeäärne kivi (Hlj, Amb, Var, Lih, Tõs, Pil, Plt, Ran, Ote) ${ }^{\frac{32}{2}}$ või (kadaka)põõsas (Aud, Ksi, Pal), samuti haud (Eisen 1897). Seda tehti enamasti 3, vahel 7 korda, mitmetel andmetel vastupäeva ja kord ka tagurpidi. Uskumusteates öeldakse, et nõida või halba inimest mattes pidi keegi pihutäie heintega ümber kaevu käima, siis eksivat kodukäija teelt (H III 9, 107 (29) < Lai). Saaremaal pidi surnuhobune esimesena koju jõudma ja ümber kaevu käima, et surnu ei tuleks koju (RKM II 3, 77 (7) < Kär). Või siis pöörati kalmistult naasnud surnuvankrit õues kaks-kolm korda ümber, põhjus ikka seesama (RKM II 3, 94/5 (47) < Kär). Arvatavasti tunnetati neid toiminguid matuselisi saatnud surnu eksitamisena.

Surnuga võidi sõita ka erilisi kujundeid. ... Siis pidi tee peal surnuga kolm korda ratast moodi risti sõitma. Siis ei hakanud enam kodu käima. (E 8729 (3) < Jõh). ... iga risttee pial sõit nad surnuga viidenurka... (H II 39, 867 (772) < Koe).

Üleüldine oli ja on, et surnu viiakse kalmistule, jalad ees. $\underline{33}$ Reegli rikkumisest arvati, et see võiks põhjustada kodukäimistki. Ja ometi, kui kellestki kardeti kodukäijat, võidi tema surnukeha viia, pea eespool, kas kodust välja (uskumusteated: Saa, Pil, Plt, Vru) või kogu tee (uskumusteade RKM II 52, 311 (51) < Ann; muistend E 18185/8 (1) < Ris) või osa sellest. Lääne-Eestist on muistendeid (ERA II 127, 319/21 (29) < Var; ERA II 56, 319/20 (20) < Lih) ja kombekirjeldus (ERA II 171, 557/8 < Kir) selle kohta, et algul on kardetud surnut viidud pea ees, siis aga poolel teel või mingis kindlas kohas (värav, risttee, sild, kivi, mille ümber kirstuga sõideti) pööratud jalad ette. Võimalik oli ka vastupidine variant: algul viidi surnut jalad, siis pea ees (muistendid: ERA II 16, 281/2 (4) < Lih; E, StK 30, 175 (17) < Phl, tegevuskohaks Lihula). $\underline{34}$

Eelkirjeldatud taigadega ühenduses torkab silma, et sageli seostub nende toimetamine mingi objekti või kohaga, millele omistati maagilisi omadusi ja millest tuleb juttu järgmises funktsionaalses tõrjerühmas. 
4. Tõkete seadmine elavate ja surnu vahele. Piir, mida kodukäija ei saanud vastavalt uskumustele ületada, võis asetseda mitmes kohas. Selleks võis olla maagiliselt kindlustatud maja (eriti künnis ${ }^{35}$ ), õuevärav või külapiir, aga ka risttee, ristipuu (s.t kalmistutee-äärne puu, kuhu matuselised tegid ristimärgi), jõgi või aed, samuti kalmistuvärav või ümber haua tõmmatud joon.

Kodunt viidava surnu järel suleti kiiresti uks $^{\underline{36}}$ ja värav. $\underline{37}$ Uskumusteated räägivad seinapragude kinnitoppimisest leinamajas (H II 12, 449 (21) < VMr; E 83583/4 (18) < Prn < PJg; Eisen 1897: 51) ning ristimärkide tegemisest ustele ja akendele.

Et surnu koju ei tuleks, löödi uskumusteadete kohaselt nael surnu aseme kohta põrandasse või seinasse (H II 40, 1105 (16) < Tln < Han; RKM II 6, 111 (69) < Kaa ja Sõrve (? Ans, Jäm); E 47811/2 (60) < Pal), kõige sagedamini aga ukselävesse (Eisen 1897: 49, 52; Loorits 1949: 81). $\underline{38}$ Künnisesse löödavaid naelu võis olla ka kolm (E 11496 (40) < Amb; H II 46, 775 (36) < Amb). Naela löömist võidi tunnetada analoogiamaagiana, surnut «kinni paneva» toiminguna, ja sellisena kuuluks see vaatlemisele järgmises funktsionaalses tõrjerühmas. Lävesse löödud nael aga viitab piiri seadmisele. Mitmel puhul on kodukäimise vastu kasutatud tarvitatud hobuserauanaelu. Muidugi tuleb naelte kui metallesemete puhul arvesse ka nende materjalile omistatav kaitsev/tõrjuv mõju. Lisaks sellele suhtuti naela kui terariistasse. Ühes uskumusteates õpetataksegi, et lävesse löödud naela terav ots peab jääma väljapoole (E $26812<$ Jõh). Ka õuevärava alla maa sisse on pandud kodukäijale tõkkeks terariistu: 9 nõela risti (E $62865(6)<$ Jäm) või vikat (H I 3, 558 (30) < Trt < Ote). $\underline{\mathbf{3 9}}$ Tõsi küll, esimesel juhul ei selgu, tehti seda matuste käigus või hiljem, teisel juhul aga toimiti nii alanud kodukäimise lõpetamiseks. D. Pruhli andmeil (E 4641 (3) < Hlj; E $25031<$ Hlj) on kodukäimise vältimiseks juba siis, kui surnu alles kodus oli, käidud kolm korda vastupäeva ümber maja, käes kinganõel, millel silm eespool ja pikk nöör taga. Surnut takistavaks peeti risti otsa pandud kolmetahulist nõela (H II 57, 187 (26) < Kos), niisamuti kui hauale viidud terariistu $(\mathrm{E} 78775<\operatorname{Prn}<\mathrm{Hl}$ s). $\underline{40}$

Kodukäijale tõkkeks on ukseläve alla elavhõbedat pandud (ERA II 273, 433/4 (73) < Kei). .11 ... Mõned olla jälle surnuaia väravale "hõbevalget» (puhta hõbeda küljest kraabitud puru) kraapinud, selle teadmise ja uskumusega, et siis olla hinged kalmistule kinni pandud, ei saavat "hõbevalgest» kuidagi üle. (ERA II 134, 633/4 (43) < Saa). Ei ilmne, millal seda tehti.

Tõkked, mis matuste käigus seati surnu teele, võisid olla ühelt poolt n-ö reaalsed ja maagilised, nagu vooluvesi, väravad (Loorits 1949: 81) või aed/aiad, millest surnu üle viidi. $\underline{42}$ Aedu võis olla üks, kolm või niipalju, kui neid teele jäi. Uskumusteates räägitakse, et surnu viidi üle kolme aia pea (s.t üle koha, kus kolm aeda kokku jooksevad) (H III 13, $366(13)<$ PJg) või aeti surnuvankriga kolmes kohas aianurka kinni (H III $12,569 / 70(12)<$ Tln $<$ Amb).

Teiselt poolt võisid takistused olla sümboolsed ja maagilised. Saaremaal oli kombeks hoida puusärgi all veeanumat, mille vasaku jalaga ümberlöömist surnu väljakandmisel motiveeriti kodukäimise vältimisega (E 62869 (38) < Jäm),,$\underline{43}$ samuti kui koduõuest teelemineva surnuvankri all veepüti ümberlükkamistki (E 73174 (1) < Jäm). Vett kallati 
ämbriga surnuhobuse jalge ette $\underline{\underline{44}}$ ja visati vankri alla, ühes teates kolm ämbritäit (RKM II 4, 470/1 (16) < Kre < Vll). Vett, liiva ja pühkmeid $\underline{45}$ heideti surnule kodust viimisel ka järele, et surnu ja kodu vahel oleks veejärv või liivamägi, millest üle äi saa (ERA II 277, 355/6 (58) < Krj). Ka setud tavatsesid heita surnule järele mulda, liiva või lund (Loorits 1949: 80). $\underline{46}$ Seejuures öeldi: ... mine jo silmist, mine meelest, kohe sinno päiivä pandass, sinnä jä̈̈ jo ü̈̈sest (ES, KT 75, $78<\mathrm{Se}$ ); aga ka: ... Mine no'ks esi, nii vii uma surm ka üteh! (H II 60, 672/91 (7) < Vas). Nende lausumiste põhjal võiks kombe liigitada kontakti lõpetavaks (1. tõrjerühm) ja paigutada lahutamisriituste hulka. Samas on kodunt viidavale surnule mulla järelepildumist seletatud ka nii: talle ju mulda vaja (KKI 61, $56(6)<$ Se). Ja see viitab juba surnu varustamisele tema uue olukorra tarvis, seostub ohverdamisega ja võiks lülituda liitmisriitustesse. $\underline{47}$ Sama lugu on ka õlle viskamisega surnule järele $\underline{48}$ (E 30546 (1) < Kaa; RKM II 3, 90 (30) < Kär; Eisen 1897: 49), mida tehes ... viskaja oli ütlend: "Sa pead öösel sääl seisma, kus sind päeval pandud." (ERA II 187, 530 (68) < Kaa).

Uskumusteate järgi ei hakkavat surnu kodus käima, kui talle ärasaatmisel peoga põhku järele visatakse, öeldes: Mine silmast ja mine meelest! (E 730 (82) < Vil), või kolm höövlilaastu järele heidetakse (ei selgu, pärinevad need puusärgitegemisest) (E 81387 (3) < KV Tartu Tütarlaste Gümn.).

Vältimaks surnu tagasipöördumist, on talle kodunt viimisel järele lennutatud veel kaikaid (EKS 403, 323 (66) < Hel = ERA II 198, 484 (71) < Hel), terariistu (Eisen 1897: 49), linaseemneid (ERA II 298 (29) < Kaa) ja soola (Loorits 1949: 81) $\frac{49}{4}$ ning tulistatud püssist kolm pauku (E $73160(1)<$ Trv).

Mitmeid surnule järelevisatavaid aineid ja esemeid on kasutatud erinevatesse paikadesse tõkete rajamiseks, nagu juba nägime (terariistad) ja veelgi näeme. Aga neid on ka lahkunule puusärki või hauda kaasa pandud, mis väljendab soovi muuta surnu paikseks (5. tõrjerühm).

Soola hoiti taldrikuga kodus kirstu all. $\underline{\mathbf{5 0}}$ Aga külvati soola nii kalmistuteele kui ka hauale, kusjuures öeldi, et surnu võib koju tulla alles siis, kui see seeme idanema hakkab (H II 71, 629 (1) < Sim) või kui sool kasvab ôrasele (ERA II 28, 145 (6) < Lüg). $\underline{\mathbf{5 1}}$

Linaseemneid on külvatud surnuaiateele nii kalmistule minnes kui ka sealt tagasi tulles (vajaduse ilmnedes ka hiljem), samuti haua ümber või hauale. Lisaks uskumusteateile räägitakse niisugusest tõrjeviisist ka muistendites ja memoraatides. Uskumuse järgi ei saa surnu enne edasi minna, kui on kõik seemned ära lugenud - tegevus, mille katkestab kukelaul. $\underline{\mathbf{5 2}}$ Mainitakse veel herneste, ubade ja humalaseemnete külvamist matuserongi jälgedele (Loorits 1949: 82). Tasub meenutada, et herned ja oad on tuntud tavanditoit, soolaga keedetud herneid ja ube anti surnuvalvajaile. Kodukäijat takistavaks on arvatud ka leinamajast teeni riputatud kuuseoksi, mille okkad tagasitulev surnu pidavat ära lugema (ERA II 37, 302 (2) < Jõh; RKM II 200, 359 (18) < Lüg). 
Väravasammaste vahele pandud puu, millest surnuvankriga üle sõideti (E 7408/9 < Rak), samuti kui puusärgi mõõduvõtmise kepp visatuna surnut vedava hobuse jalgu (H III 17, 290 (20) < VMr < Kad), pidi olema takistuseks tagasipöörduvale surnule. Viimaseks piiriks olid pärast matmist labidaga ümber haua tehtud ringid (ERA II 166, 232 $(60)<\operatorname{Iis}<\operatorname{Trm}) . \underline{53}$

Uskumusteates räägitakse, et matmast tulnuna viskasid surnuvedajad õlgi üle müüri kalmistule vältimaks surnu kodukäimist (H II 26, 1006 (128) < Plt, Loorits 1949: 82). Toimingu tähendus võiks seostuda nii kontakti lõpetamisega (1. tõrjerühm) kui ka tõkke seadmisega. Just viimane oli põhjuseks, miks tagasiteel kalmistult visati surnuvankrist või -reest esimesel ettetuleval sillal õled maha (E $25030<\mathrm{Hlj}$, Loorits 1949: 82; E 37954 (3) < Kad). Kardetud surnu asemeõled viidi kuhugi ristteele, sest siis minevat surnu nende juurde ega tulevat koju (H II 15, 23 (66) < Kuu). $\underline{\mathbf{5 4}}$

Väga levinud oli ristimärgi tegemine lisaks kodumaja ustele ja akendele veel oueväravasse, kalmistuteele (eriti ristteedele), hauale, kalmistuväravasse ja teeäärsetesse puudesse $\underline{\mathbf{5 5}}$ (Eisen 1897: 48 ja 51; Loorits 1949: 83) piiritähiseks, millest surnu kodu poole ei pääse. Puusse risti tehes öeldi Tudulinnas: ... seije saadik tohid tulla ja mitte kaugemalle [--] (H II 7, 783/4 (104) < Iis). Ristimärke lõigati puuse üks või kolm ja seda tehti kas teel surnuaiale või tagasi tulles (Eisen 1897: 48). Ka mujale tehtavate ristimärkide arv oli üks, kolm, harvem seitse (Eisen 1897: 47-48). Maapinnale tehti mõnigi kord riste esemetega, millel usuti olevat tõrjeomadusi, nagu raudkang, -labidas, kirves (E, StK 42, 202/3 (30) < Muh), kadakakepp (Eisen 1897: 50), pihlakavits (E 74543 (2) < Jäm), või - eriti hauale - vasaku jala kannaga.

On teateid punase lõngaga kokkuseotud lepapulkadest ristikeste (ERA II 38, 274 (7) < $\mathrm{VMr})$ või viie pihlakapulga (ERM 164, $27(1)<\mathrm{MMg})$ hauale asetamisest ning seitsme haavakiilu hauakünkasse löömisest (E $86273 / 5(1)<$ Se) kodukäimise kartusel. $\underline{\mathbf{5 6}}$

Saaremaalt on teateid (teeäärsete) puude latvade murdmisest, et surnu koju ei tuleks (E 17999 < Khk; E 25525 (12) < Khk; RKM II 73, 95 (5) < Kih; Eisen 1897: 48; Loorits 1949: 83).

Setudel oli kombeks Tailova surnuaialt tulles kilomeeter või pool eemal teenurgal peatada matuserong, et surnu saaks maha minna. Seejuures öeldi (vastavalt olukorrale) näiteks: Laskõ nüüd ema mahha (KKI 61, 187/8 (6) < Se, Tääglova k) või Noh, surnu, hüppa maha! (KKI 61, 40 (3) < Se, Tepja k).

5. Surnu kirstu või hauda kinnipanemine. Piiri seadmine surnu ja elavate vahele läheb sujuvalt üle tema hauda sulgemiseks haua piiramise, tõkestavate märkide tegemise ja maagiliselt takistavate ainete või esemete asetamisega hauale. Surnu kinnipanekut taotleti ka samade ainete ja esemete kirstu või hauda kaasapanemisega.

Surnu rinnale asetatud ristike pidi kaitsma surnukeha kurjade jõudude eest. Mõne teate kohaselt käsitati seda aga kodukäimist takistava esemena (H III 17, 977 (67) < Amb; pihlakarist - ERA II 274, 648/9 (76) < Räp). $\underline{58}$ 
Lisaks pihlakapulkade surnu jalge alla panemisele (mida on vaadeldud 2. tõrjerühmas) on neid asetatud ka kirstu põhja (E 83562 (12) < Prn < Pär). Leidub kirjeldus mulgi matustest Alatskivi surnuaiale, kus haua nurkadesse olevat pandud üheksa lepapulka vältimaks surnu koju tulekut (KKI 1, 154/5 (141) < Kod). Uskumusteate järgi hoidis puusärgi peale asetatud haavaroigas ära kodukäimise (E 25524 (8) < Khk; Eisen 1897: 48).

Samal põhjusel, miks linaseemneid teele või hauale külvati, on neid ka kirstu kaasa pandud (H II 46, 737 (61) < Amb; E 13578 (20) < Koe). Ka olevat terariistu (nuga, vikat) surnukirstu asetatud (Eisen 1897: 50).

Puusärki, hauda või ristimulku poetatud (hõbe)raha võiks aga pidada ohvrianniks või kaasapanuks, mis kuulub liitmisriitustesse.

Kohalikus muistendis räägitakse paha mehe puusärgi köitega kinnisidumisest, et surnu välja ei pääseks.

Mõnes uskumusteates (E XI $54\left(144^{\mathrm{c}}\right)<\operatorname{Sim}\left(\right.$ ?); ERA II 10, $421(46)<\mathrm{HMd}<\mathrm{Kul}$; E $8^{0} 13,73$ $(212)<$ Plv) on peetud kodukäimist ärahoidvaks seda, kui surnuga kalmistule sõites keegi puusärgil istub. O. Looritsa järgi pidi see olema surnu lähim sugulane, põhjusel, et surnu ei saaks teda kaasa võtta (Loorits 1949: 82). $\underline{\mathbf{5 9}}$ Tundub, et tegemist on vana kombega, mida üleskirjutamise ajal enam ei peetud, kui ka mäletati.

Enne matmist koputati kirstule või kirstunaeltele, $\underline{\mathbf{6 0}}$ erandjuhul löödi kübaraga kolm korda kirstu otsa pihta (H II 22, $465(56)<\mathrm{Hl}$ ). Enne haua kinniajamist löödi vasaku jala või kadakakepiga (E XI $54\left(144^{\mathrm{d}}\right)<\operatorname{Sim}($ ?); E $46439 / 40(16)<$ Pal) vastu kirstu $($ E $83584(24)<$ Prn < PJg), pärast matmist vastu risti (H IV 4, 338 (8) < Trv; Eisen 1897: 50). Rohkesti andmeid on vasaku jalaga, ka vasaku jala kanna või varbaga hauakünkale koputamisest (enamasti kolm korda). Seda on tehtud nii matuste käigus kui ka hiljem kodukäimise lõpetamiseks. Toimingut on mõnikord saatnud sõnumine, nagu Siin pead sa magama! (E 83584 (24) < Prn < PJg), või Igavest, igavest, igavest! (E $59984(57)<\mathrm{MMg})$. Seesuguse tõrje kohta on arvukalt uskumusteateid. Seda kohtame muistendeis (eriti tüübis Aa S 6 «Sulane paneb isanda hauda kinni», kus nõnda lõpetatakse juba alanud kodukäimine), memoraadid on haruldased. Uskumusteade räägib ka pahema jala kanna peal haual ümber keeramisest (H III 2, $141(9)<\mathrm{Hlj}$ ).

Erakordseid surnuid (nõiad, halvad inimesed) on maetud kummuli $\underline{61}$ või ka hiljem hauas kummuli keeratud, harvem on asetatud neil jalad päitsisse. Sellegi kombe kohta on rikkalikult uskumusteateid, vähem muistendeid ja vaid üksikuid memoraate. $\underline{\mathbf{6 2}}$

Sageli - eriti eelneva kodukäija-kartuse puhul, mida tunti erakordsete surnute ees - kasutati kombineeritud tõrjet. Kui paljudel juhtudel oldi kindel tõrjemaagia tõhususes, siis teiselt poolt jutustati ka muistendeid, kus surnu vaatamata matjate ettevaatusabinõudele ikkagi koju tuleb.

Eestis tuntud kodukäija tõrjeviisid ja -vahendid on, nagu nägime, ühised mitmete soomeugri ja teiste rahvastega, sageli lausa universaalsed. Toodud võrdlused ei ole täielikud, vaid sõltuvad autoril kasutada olnud kirjandusest. Täielikuma võrdlusmaterjali andmine eeldaks iga konkreetse tõrjeviisi leviku üksikasjalikku uurimist, milles ammendavate tulemusteni saaks jõuda kombestikuatlase abil. 


\section{Kirjandus}

Ariste, P. 1974. Vadjalane kätkist kalmuni. Emakeele Seltsi Toimetised nr 10. Tallinn. Eisen, M. J. 1897. Kodukäijad. Katse nende iseloomu seletamiseks ja 40 juttu surnute hingede ilmumisest. Narva.

Eninsh, E. 1981. Läti põlispuud. Eesti Loodus nr l, lk 8-16. Tartu.

Gratshova, G. N. 1983. Traditsionnoje mirovozzrenije ohotnikov Taimõra. (Na materialah nganasan XIX - natshala XX v.) Leningrad

Gurvitsh I. O. 1987. Novõje dannõje po traditsionnoi obrjadnosti korjakov. Traditsionnõje verovanija i bõt narodov Sibiri XIX - natshalo XX v. Novosibirsk.

Harva, U. 1948. Suomalaisten muinaisusko. Porvoo, Helsinki.

Hlobõstina M. D. 1987. Govorjashije kamni. Sibirskije mif i arheologija. Novosibirsk.

Holmberg (=Harva), U. 1914. Permalaisten uskonto. Porvoo.

Holmberg (=Harva), U. 1915. Lappalaisten uskonto. Porvoo.

Honko, L. 1964. Siirtymäriitit. Sananjalka. Suomen Kielen Seuran vuosikirja 6. Turku.

Honko, L., Pentikäinen, J. 1970. Kulttuuriantropologia. Porvoo, Helsinki.

Karmõshova B. H. 1986. Arhaitsheskaja simvolika v pogrebal'no - pominal'noi obrjadnosti uzbekov Ferganõ. Drevnije obrjadõ, verovanija i kult'õ narodov Srednei Azii. Istoriko etnografitsheskije otsherki. Moskva.

Kemppinen, I. 1967. Haudantakainen elämä karjalaisen muinaisuskon ja vertailevan uskontotieteen valossa. Karjalan tutkimusseuran julkaisuja l. Helsinki.

Kenin-Lopsan M. B. 1987. Obrjadovaja praktika i fol'klor tuvinskogo shamanstva. Konets XIX - Natshalo XX v. Novosibirsk.

Konkka U. S. 1980. Semeinõje obrjadõ. Duhovnaja kul'tura segozerskih karel kontsa XIX natshala $X X v$. Leningrad.

Kulemzin V. M. 1984 Tshelovek i priroda v verovanijah hantov. Tomsk.

Kulemzin, V. M. Lukina N. V. 1977. Vasjugansko - vahovskije hantõ v kontse XIX - natshale $X X v$. Etnografitsheskije otsherki. Tomsk.

Laugaste, E. 1963. Eesti rahvaluuleteaduse ajalugu. Valitud tekste ja pilte. Tallinn.

Laukkanen, M. 1972. Viron Ingerin luterilaisten vainaja-rituaali. Cum laude -esitelmä professori Juha Pentikäisen uskontotieteen seminaarissa 20. marraskuuta 1972. Käsikiri. Lavonen N. 1984. Funktsional'naja rol' poroga v fol'klore i verovanijah karel. Fol'klor $i$ etnografija. U etnografitsheskih istokov fol'klornõh sjuzhetov $i$ obrazov. Leningrad.

Lehto, L. 1982. Syylliset kotonakulkijat. Suomalaisen ja vertailevan

kansanrunoudentutkimuksen I harjoitusaine humanistisen tiet. kandidaatin tutkintoa varten toukokuussa 1982. Helsinki.

Loorits, O. 1927. Liivi rahva usund II. Tartu.

Loorits, O. 1948. Eesti rahvausundi maailmavaade. Stokholm.

Loorits, O. 1949. Grundzüge des estnischen Volksglaubens I-III. Uppsala - Lundequist;

Köpenhamn - Munksgaard. Lund. Skrifter utgivna av Kungliga Gustav Adolfs Akademien 18: $1-3$.

Mokshin N. F. 1968. Religioznje verovanija Mordvõ. Istoriko - etnografitsheskije otsherki.

Saransk.

Pentikäinen, J. 1968. The Nordic Dead-Child Tradition. Nordic Dead-Child Beings. A Study in Comparative Religion. FFC 202. Helsinki.

Sem T. Ju. 1986. Religioznõje predstavlenija tunguso - man'dtshzhurskih narodov o zhiznennõh silah tsheloveka i ih vmestilishshah. (Po fol'klornomu i etnografitsheskomu materialam.) Fol'klor i etnografija narodov Severa. Mezhvuzovskij sbornik nautshnõh trudov. Leningrad. 
Simonsuuri, L. 1961. Typen- und Motivverzeichnis der finnischen mythischen Sagen. FFC 182. Helsinki.

Suurhasko J. J. 1985. Semeinõje obrjadõ i verovanija karel. Konets XIX - natshalo XX v. Leningrad.

Shmits, P. 1936. Latvieshu pasakas un teikas. Riia.

Toporov V. N. 1987. Zametki po pohoronnoi obrjadnosti. Baltoslavjanskije isledovanija.

Moskva.

Turi, J. 1979. Kertomus saamelaisista. Porvoo.

Valk, H. 1987. Teine ilm ja hauapanused. [Käsikiri.]

Vilkuna, K. 1968. Vuotuinen ajantieto. Vanhoista merkkipäivistä sekä kansanomaisesta

taloussääkalenterista enteineen. Toinen, korjattu ja lisätty painos. Helsinki.

Vilkuna, J. 1979. Vainajan karsikko Suomessa. Suomalaisen ja vertailevan kansantieteen progradu-työ Jyväskylän yliopistossa marraskuussa 1979.

Viluoja, E. 1978. Sõnamaagia kodukäija tõrjes. Sõnast tekstini. Tallinn

Viluoja, E. 1982. Demonic Dead in Estonian Folk Tradition. Suomalais-neuvostoliittolainen itämerensuomalaisen filologian symposiumi 30.8-2.9. 1982. Jyväskylä. Esitelmien referaatit. Jyväskylä.

Virtaranta, P. 1964. Lyydiläisiä tekstejä III. Suomalais-ugrilaisen Seuran Toimituksia 131. Helsinki.

\section{Kommentaarid}

1. Ajaliselt langeb eestlaste hingedeaja sisse Soomes ja Eesti põhjarannikul tuntud jaguaeg (jakoaika) oktoobris-novembris (Vilkuna 1968, 246-247). K. Vilkuna, toetudes U. Harvale, peab jaguaega kahe aasta vahele jäävaks ajaks. Muinassoomlaste aasta lõppes sügisese saagikoristusega mihklipäeva paiku. Uus aasta algas 11-12 päeva pärast, sest triivi vältimiseks tuli kuuaasta sobitada päikeseaastaga. Jaguajal arvati liikvel olevat kummitusi. Aasta algust tähistati taluti erinevatel õhtutel koos külalistega. Samal ajal käisid akende taga kolistamas maskeeritud kontvõõrad, kes peremehe väljudes põgenesid. Kui keegi neist tabati, kostitati teda aukülalisena. $\mathrm{K}$. Vilkuna arvab, et kontvõõraste nimetus vilpus ja tegusõna vilpustella viitavad vististi apostel Filippusele, kelle mälestuspäev on 14. XI. Vaidlustamata antud etümoloogiat, on siiski huvitav tähele panna, et sõnad «vilbus» (verbid «vilbatama» ja «vilbastama») (Krk, Hel, Trv, Pst) ja «ilppus» (TMr) tähendavad Eestis viirastust, nägemust või nõidust.

2. A. van Gennepi teosele «Les Rites de Passage» (Paris 1909); «The Rites of Passage», (Second Impression, London 1965) on viidatud kaudsete allikate põhjal: Honko, Pentikäinen 1970: 60; Laukkanen 1972. Eesti keeles on kasutatavad ka terminid irrutamis-, ülemineku- ja ühendamisriitused.

3. Riituste rühmitamisel van Gennepi skeemi järgi ei olda üksmeelsed. Ka pole van Gennep piisavalt iseloomustanud riituskategooriate jaotuskriteeriume (Laukkanen 1972). Siinne rühmitamiskatse on autori meelest üks võimalikke, kuid ei pruugi ühtida teiste omasugustega. Nii mainib van Gennep, et vastupidiselt oodatule ei tõuse lahutamisriitused matusekombestikus esiplaanile. Siinkirjutaja arvates on nad aga küllaltki arvukad. Ons küsimus materjali erinevas interpreteerimises või eri rahvaste materjalide erinevuses? 
4. Siin ja edaspidi on allikaviide või -viited toodud vaid siis, kui tegemist on ühe või mõne teatega. Akende ja uste avamise komme suremise kergendamiseks on muidugi esindatud rohkete teadetega. Artiklis viidatud juhtumil aga on kombe mittetäitmise sanktsiooniks kodukäimine.

5. Peegli katmist suremise ajaks on käsitatud hingeheitmist kergendava riitusena, seda ka Ingerimaa lääneosas (Laukkanen 1972). Ometi kaeti peegel Eestis enamasti selleks ajaks, mil surnu majas oli, kas põhjust teadmata või eesmärgiga vältida surnu peegeldumist, mis omakorda põhjustaks kodukäimist.

6. Põhjakaart on seostatud eemaldamise, kaotamise, hävitamisega. Eluhoonetest põhja poole visati aineid ja asju (mõnes kohas ka surnupesuvesi), millest kardeti midagi halba külge hakkavat. Kodukäija hävitamiseks on tulistatud hõbekuulidega "põhjatuule poole» (E, StK 39, 92/3 (66) < Khk).

7. Puhastusriituste puhul võib ühe ja sama menetluse eesmärgiks olla nii surma, surnust saadavate haiguste kui ka kodukäimise vältimine.

8. Eriliselt kardetud surnute puhul on esimene laast (muistend, ERA II 32, 438/41 (17) < VMr) või kolm esimest laastu (uskumusteade, H II 53, 526/7 < Sim), mis puusärgi tegemisel laua küljest lahti löödi, pandud kirstu põhja.

9. Memoraadis jutustatakse: ... Kerstu lauast jäänud üks tükk järele, neli arssinad või. Sis /kodukäija/ pannud [selle] sinna lakka sarika najale ja las'k liugu säält alla perset pidi (KKI 1, 227 (336) < Kod). Siin ja edaspidi on näitetekstid esitatud võimalikult originaalilähedaselt. Parandatud on ainult ilmseid kirjavigu ja interpunktsiooni.

10.Teadupärast üritatakse mõnikord (taigade abil või ilma) oma häda teiste kaela veeretada, nii ka kodukäijat. Kui kardetakse, et surnu kodu käima [h]akkab, siis tehtakse kerstu-mõõdupuuga teise talu ümber üks ring, siis [h] akkama ta sinna käima (H II 26, 1006 (133) < Plt). Teadmata on, kas kodukäimise vältimiseks võõraste hobuste surnuvankri ette rakendamine sama eesmärki teenis (ERA II 28, 327 (3) < Lüg).

11.Kellegi poolt (maagiliselt) kahjustatud objekti suitsutati kahjustajalt võetud materjalide suitsuga. Seda mõtteviisi (kas otseses või kaudses tähenduses) väljendab ka vanasõna: Kelle koer on hammustanud, selle karvadega tuleb suitsetada (Rid - E. Viluoja < Kalju Viluoja.) Siin nähtavasti püütakse surnu juuste põletamisega potentsiaalset kodukäijat ette neutraliseerida.

12.Õue pühkimist võib mõista ka jälgede segamisena kodukäija eksitamiseks (vt allpool tõrje 3. funktsionaalne alarühm).

13.Vrd esemete ja ainete surnule järeleheitmisega 4. tõrjerühmas.

14.Ahju puudutamine matuselt naasnute poolt on siinkirjutajale teada setude ja lüüdi karjalaste tavana. Folklorist Veera Pino kirjeldas (26. III 1987) selle kombe täitmist setudel nii: Peielised, surnuaialt tagasi tulles, puudutasid ahju, vist kriibiti ahjule näpuga kolm risti: "Ah'oeläjille kuul ja katsk!" Lüüdi karjalastel oli matmast koju jõudnuina esimeseks toiminguks panna mõlemad käed natukeseks ajaks ahju vastu, et oleks vähem leina kadunu pärast (Virtaranta 1964: 207). Mis õieti on selle kombe tagapõhi? Näen siin mitut võimalikku seletust. 1. Matuseliste inkorporeerimine kodupiiri kontakti kaudu ahju kui kodukoldega (millega ju jällegi seostub oma uskumustering, vt nt Sem 1986: 65-70; Hlobõstina 1987: 40). 2. Kontakt ahju kui puhastus- ja tõrjemaagias kasutatavate ainete - tule, suitsu ja tuha - asupaigaga. 3. Püüd suunata surnu/surma kahjulikku mõju eneselt teisele objektile (ahjuelajatele 
(Se)). 4. Soov surnu/surma mõju abil hävitada parasiitputukaid (Se), nagu seda neid surnule kaasa panneski on loodetud teha. J. Suurhasko nimetab seda zhesti «puhastavaks» ahju puudutuseks (Suurhasko 1985: 56-57).

Järgmine uskumusteade valgustab veidi nihutatud nurga alt ahju osa kodukäimise ärahoidmisel, toetades eeltoodud hüpoteesidest esimest: Kui üts kuri ja halv inemine ära kooles, siis peävä selle koolja rõiva, mes tema kirste pääl omava, nee rõiva vissadago ahjo perä vai kummi pääle, siis ei nakkavad koolja mitte kodo käümä. (H II 68, 729/30 (4) < Räp). Eks meenuta see äratulnud piimahamba ahju peale heitmise kommet! Kas tahetakse käesoleval juhul kaasata ahju- (=maja)haldjat kodu kaitsmisele vaenuliku surnu vastu? Kodu kaitsmine oli eesmärgiks ka maja ja tema ümbruse kindlustamisel või piiramisel märkide ja esemetega, millele omistati kaitsevõimet (4. funktsionaalne tõrjerühm). Karjalas sidusid lähisugulased matuste aegu kalmistule minnes kaitseks kalma vastu pea- või kaelarätikusse väikesi ahjust võetud kivikesi, mis koju jõudes ahju alla visati (Suurhasko 1985: 82-83).

15.Nii tehti ka Eesti-Ingeris (Laukkanen 1972: 14).

\section{Kooljat valvote ja pallõlde koolja man tuuperäst, et kurja vaimo koolja mant ärä} hirmutade ehk mitte koolja mano laskõ, kuri vaim tükvät koolja mano hullõmbidi, kui uni inemise mano. Kooljat pimeüse kunage es jätetä; kui hämäräs õdago läts minemä, võete tuli üles ja tuli palle kunni hummogo suurõ valgõni. (ERA II 274, 602 (4) < Räp). (Surnukeha kaitseta jätmise mõningate tagajärgede kohta vastavalt uskumusteadetele ja muistenditele vt nt Viluoja 1982).

17.Inimesest, kes jäi oma surma momendil üksinda, kardeti kodukäimist.

18.Kuigi mõlemad teated esinevad ainult J. Hünersoni kirjapanekus, väärivad nad tähelepanu, sest hobust leivalabidaga pekstes on tõrjutud temalt luupainajat (E $28054 / 5$ < Tveri - M. Riste 1886). Võib-olla omistati leivalabidale kaitse- või tõrjeomadusi tema kontakti tõttu ahjuga/tulega või leivaga? Karjalased on heitnud surnukirstu asemele kõrvuti raudasjade ja veega ka leiba (Konkka 1980: 26; Suurhasko 1985: 82) ning asetanud surnu väljakandmise ajaks lauale leivaastja (nagu venelasedki).

Muide: V. Toporov (1987: 20-23) püüab seostada muinasjuttude (leiva)labidat, millega Baba-Jaga tahab ohvrit ahju tõugata, surnute põletamise rituaalis kasutatud labida või kühvliga.

19.Viidatud teoses kirjutab O. Loorits juustest, küüntest ja hammastest kui hingejõu asupaigast vastavalt rahvausundile. Ta mainib äralõigatud küünte ja irdunud hammaste, mitte aga juuste surnule kaasapanemist. H. Valgu järgi pandi surnule juukseid kaasa Rapla, Karja, Kihelkonna ja Pärnu kihelkonnas (Valk 1987).

20.Vt arutlust ainete ja esemete surnule järeleheitmise üle 4. tõrjerühmas.

21.Arusaam - surnule vastupidi kui elavale - on omane paljudele rahvastele. Nii näiteks kängitsesid vadjalased surnul erinevalt elavast vasema jala esimesena (Ariste 1974: 150); korjakid vahetasid surnul parema ja pahema käe kinda (Gurvitsh 1987: 83). Kummalgi juhul tõrjet ei mainita. Kui nüüd mõnel puhul surnule rõivaste pahempidi selgapanekut seostati kodukäimise ärahoidmisega, võis see ehk toetuda mõttekäigule: elavatest erinevalt - s.o surnu kombel - riietatuna kuulub surnu ka surnute maailma, siinpoolsusse pole tal seega asja. Niisiis võis komme olla osa liitmisriitusest.

22.Surnu riiete kokkuõmblemine oli tuntud ka karjalastel (Kemppinen 1967). 
23.Halvakombeliseks peetud surnute jalgade sidumist on täheldatud ka soomlastel (Harva 1948: 498).

24.Vadjalased pigistasid surnu vasaku jala varbaid surnukartusest ülesaamiseks (Ariste 1974: 171). Eestiski öeldi laiba jalga muljudes: Vii oma hirm, vii oma arm! Eesmärgiks oli aga kodukäimise vältimine. Kodukäija tõrjesõnu ja nende seoseid taigadega olen käsitlenud mujal (Viluoja 1978).

25.Kirjeldatud meetodi tugevdatud variandina võiks käsitada surnu jalgade läbilöömist pihlakapulkadega, mida kasutati vastavalt uskumusteatele juba alanud kodukäimise lõpetamiseks (ERA II 148, 11 (4b) < Mär), niisamuti kui laiba läbilöömist haavateibaga (ERA II 162, 450/4 (3) < Ludza 1.), haavateiba löömist läbi maamulla kirstuni (ERA II 33, 55 (6) < Lut) või surnu pea maharaiumist (H II 15, $700<$ HJn; ERA II 162, 450/4 (3)) (mis aga ei mahu matusekommete käsitlusse).

26. Naela löömist läbi kirstu surnukehasse tasub kõrvutada kirstunaeltele, puusärgile või hauakünkale koputamisega (5. tõrjerühm). 2. ja 5. tõrjerühmal on puutepunkte, mis tingib vastastikuseid viiteid. Rühmadevahelise (hajusa) eraldusjoone ühele poole jääb manipuleerimine laibaga, eesmärgiks muuta see liikumisvõimetuks, teisele poole surnu otsene või maagiline kirstu või matmiskohta kinni panemine.

27.Komme on tuntud ka udmurtidel (Holmberg 1914).

28.Kui Jaagu eit ära suri, oli üteln, et ärge mind sedaviisi matke kui teist inimest. Viige põllalt läbi vastoksi. /.../ Muidu tuleb koeo (ERA II 56, 319/20 (2) < Lih). Seda, et surija ise õpetab, kuidas hoiduda kodukäimisest, tuleb rahvapärimustes ette mitut puhku.

29.Isegi hingedeaja külalisi - hingi - paluti ärasaatmisel minna teed, mitte põldu mööda, nagu ilmneb Th. Hjärne kroonikast (Loorits 1948: 111).

30.See meenutab paljude rahvaste tava viia surnu välja mitte uksest, vaid läbi spetsiaalselt selleks hoonesse tehtud avause, nagu see on olnud kombeks näiteks saamidel (Holmberg 1914), udmurtidel (Holmberg 1915), hantidel (Kulemzin 1984: 140), aga ka tuvalastel, kes kandsid shamaani surnukeha, külg ees, läbi avause jurtaseinas (Kenin-Lopsan 1987: 85). Põhjendused kombele on erinevad. Kui handid toimisid nii selleks, et surnu ei tuleks tagasi, siis usbekid viisid surnu välja akna kaudu, mis pidi vältima uusi surmajuhtumeid selles majas (Karmõshova 1986).

31.Surnu eksitamine kirstu keerutamisega oli tuntud nt ka udmurtidel (Holmberg 1914; Kemppinen 1967).

32.Türi muistendis ei taotleta ümber kivi käimisega kodukäija eksitamist, vaid sel viisil saab üleloomulikult raske surnu taas kergeks.

33.Nii on kombeks ka karjalastel. Mõnest Karjala külast on aga teateid, et varasematel aegadel kanti surnu majast välja pea eespool (Konkka 1980: 26).

34.Uskumusteatest H II 53, 526/7 (672) < Sim, kus on juttu nõia matustest, ei selgu üheselt, millist tegevust kirjeldab väljend ... pöörati puusärk risttee peal ümber... Seetõttu jääb see teade tõrjemeetodite funktsionaalsel rühmitamisel arvestamata.

35.Lävest kui piirist, samuti läve seosest surnutega on kirjutanud N. Lavonen (1984).

36.Nii tehti ka Ingerimaa lääneosas, et «vaim» ei tuleks tagasi (Laukkanen 1972: 13). 
37.Värava kohest sulgemist surnukeha läbiviimise järel on põhjendatud nii mahajäänud kodakondsete surma vältimise (KKI 10, 283/4 (1) < Mus) kui ka surnu tagasituleku takistamisega (RKM II 6, $112(73)<$ Kaa ja Sõrve).

38.Liivlased on löönud naela surnu pesemise kohta (Loorits 1927: 2), vadjalased lautsisse (laavitsasse) (Ariste 1974: 186), karjalased lautsi kohta põrandasse (Kemppinen 1967) ja lävepakku (Konkka 1980: 26; Suurhasko 1985: 82). Kuigi karjalasedki põhjendasid naela löömist kodukäija takistamisega, peab J. Suurhasko viidatud teoses nii selle kui teistegi kaitse- või tõrjeiseloomuga matusekommete puhul algseks kahjuliku surmaväe (kalma) neutraliseerimist.

39.Niipea, kui puusärk väljakandmiseks üles tõsteti, asetasid karjalased sellele kohale mõne raudeseme (Konkka 1980: 26; Suurhasko 1985: 82). Handid panid pärast surnu väljaviimist künnisele kirve või noa (Kulemzin 1984: 140). Mordvalaste tava kohaselt heitis kodakondseist vanim pärast matuseliste kalmistult naasmist eeskotta noa, et surnu ei tuleks majja (Mokshin 1968: 51).

40.Kui kodukäija takistuseks mõeldud ese või aine viiakse otse hauale, kui matmispaik ümbritsetakse tõkestava piirjoonega, siis tähendab see sisuliselt surnu hauda kinnipanekut (5. tõrjerühm). Siiski on materjali kompaktsema esituse huvides mitte hajutada sama tõrjeviisi taigade sooritamise kohast lähtudes.

41.Võrdluseks: laplastel on uskumus, et surnu ei tülita seda, kes kannab kaasas elavhõbedat (Turi 1979).

42.... Ja viidi teda tee pealt natuke kõrvale, et aed maha võtta ja surnu sealt läbi viia: siis ei tule kodu käima. /-/ Ja siis võeti aed maha ja surnu viidi sealt aia-august välja ja aed tehti kohe üles. I-/ (ERA II 32, 438/41 (7) < VMr).

43.Karjalasedki läigitasid kirstuasemele vett (Konkka 1980: 26; Suurhasko 1985: 82).

44.Kui inimene ära sureb ning kardetakse, et ta akkab kodu käima, siis surm tuleb merest läbi viia. Seda tehakse sedaviisi. Kui surm juba obuse pääle pandud on ning akatakse ää viima, siis tuleb ämbriga obusele juua anda. Obusele äi tohi selle pääva ennemini juua anda. Kui siis obu ühe ämbritääve ää joond on, tuleb teine täis obuse jalge ede ümber kummuta. Ohjad peavad ühtejooni teise kää akkamas olema ning kohe minema, nenda et obu säält vee sihest läbi läheb, siis surm ei saa änam tagasi tulla. (RKM II 24, 448 (33) < Pha).

45.Kui surnule järeleheidetavad pühkmed pidid puusärgi asemelt pühitud olema (H II 26, 1006 (27) < Plt), võib selles näha kontakti katkestamise taotlust.

46.Surnule on mulda järele heitnud ka Lutsimaa eestlased, kuid põhjuse kohta teated puuduvad (E, StK 28, 98 (8) < Lut).

47.Kombe tagapõhja otsides tahaks paralleelselt peatuda tänini üldisel mullapeotäite hauda viskamisel matuseliste poolt. Setumaal öeldi selgi puhul: ... mine jo silmist, mine meelest (KKI, MT 19, 65 < Se). Põltsamaal ... Ristiema käskis kolm korda mulda auda visata, siis pidi surnukartus ära kaduma (KKI, 13, 320/1 (3) < Plt). Eesti-Ingeris visati hauda kolm peotäit liiva, et lahkunu muutuks maaks ega hakkaks koju käima (Laukkanen 1972: 13). Pilistveres usuti: Siis kui kodust mulda ligi võetama (matmisel?), siis ei pea ennam surnu kodu tulema käima (H III 30, 976 (17) < Pil).

48.Järgnevalt mõned lõigud kirjapanekutest, kus räägitakse joogi (õlle) ohverdamisest surnule. Sebastian Münster (1489-1552) «Von seltzamen Breuchen, die in Lyfflandt sind»: Ja kui nad oma surnuid hakkavad matma, istuvad nad maha surnu ümber, hakkavad jooma ja toovad surnule ka ja valavad tema osa tema peale. Johann Arnold v. 
Brand (1647-1691) «Der Lieffländer Begräbniß-Ceremonien»: ... igal aastal nelipühade ajal peavad minema kõik lahkunu sugulased ... samale hauale, nad kastavad seda / hauda/ joogi või ôllega... (vt Laugaste 1963: 24 ja 80.)

49.Tulise tuha ja hõõguvate süte surnule järeleviskamist on eespool nimetatud puhastusriituste hulgas kui ühte kontakti lõpetamisele suunatud abinõudest. Tuhka ja süsi kasutati mitmesuguse kurja mõju neutraliseerimiseks. Kui arvati, et surnu juba käibki kodus, riputati maja ümber takistuseks tuhka, linaseemneid või soola.

50.Muidugid, kus surm kerstuge oli, siis veekapp oli ikke kerstu all, soola taldrik oli ka... (RKM 3, 77 (7) < Kär). Võib-olla loodeti, et see aitab kaasa surnukeha paremale säilimisele? Siinkirjutaja mäletamist mööda pandi Torma kihelkonnas äikese ajaks surnukirstu alla raudese, et laip üles ei tursuks. Võrdluseks: Kui surnu kambren ollu ja sel aal sõs kõvaste müristanu, sõs pantu kirves kirstu alla, sest muidu tulevat surnu ellu. (ERA II 282, 410 (38) < Trv). Kuidas seda mõista? Surnukeha ülestursumist seletati rahvapärimustes mõnikord sellega, et vanapagan/kurat tunginud kaitseta jäetud surnu nahka. Sel puhul oli ka kodukäimist karta (Viluoja 1982). Teadupärast arvati ka, et välk ohustab vanapaganat (aga ka kodukäijat), kes müristamise ajal püüab varjuda. Pole võimatu, et siin on need või veel mingid uskumused seostunud. Sel juhul oleks tegemist surnu kaitsmise kui üleminekuriituse osaga, kusjuures sool ja terariist oleksid maagilise kaitsevahendi funktsioonis. Veeanumast kirstu all oli juba eespool juttu. Vett, soola ja metalli võib käsitada ka puhastusmaagiliste vahenditena.

51.Soola külvamine kodukäija takistuseks on tuntud Virumaal, aga ka Muhu saarelt on vastav teade (E, StK 42, $215(41)<$ Muh).

52 ... siis ta oli rääkind oma ristipojale, ... et siis Nigula risttielt, et võttage külvage kaks toopi linaseemneid kuni surnuajani. Et kui jõuan ennemb ära lugeda need linaseemned, kui kukk laulab, siis tulen kodo ikkagi. ... Kui oli surd, siis oli siit risttie pialt sinna Viru-Nigula puole, sinna surnuajast saadik oli külvatud kaks toopi linaseemneid, no aga linaseeme on jo nii peenikene nii kui pisikene räbalakene. ... Aga juba ta ikka vist siis ei jõudand ära lugeda, sellepärast et kukk ennemb laulas ja nii et vähemalt ei nähtud, et vanames oleks kodo tuld. (KKI RLH 75:5 (16) < VNg.)

53.Udmurtidel oli kombeks tõmmata kirvega põiki üle tee jutte, et surnute hinged ei järgneks matuselistele (Holmberg 1914); samal põhjusel panid handid matusepaigalt lahkudes enda jälgedega risti toomingakepi (Kulemzin, Lukina 1977: 162; Kulemzin 1984: 145). Labidaga haua piiramine on tuntud mordvalastel (Mokshin 1968: 51).

54.Et surnu koju ei tuleks, selleks on tema järelejäänud riided kodunt ära viidud (H II 65, 749 (7) < Jür; ERA II 41, 514 (45) < Jür), muistendites kodukäija teele silla alla (ERM 163, 21 (66) < Rid; ERA II 55, 98 (13) < Rid; ERA II 55, 140/3 (17) < Rid).

55.Kui ristide tegemiseks oli kindel puu, kutsuti seda risti-puuks (või liigi järgi ristipedäjäks, risti-kuuseks), ka virve-puuks (Loorits 1949: 83). Risti-puud olid tuntud Soomes ja Karjalas (Kemppinen 1967), kus vastava puu nimetus oli ristikko (Loorits 1949: 83) või karsikko, sest puu alumised oksad olid ära laasitud (Vilkuna 1979), ning Lätis Shmits 1936, Eninsh 1981). Ladvani laasitud ohvripuudest eestlastel on kirjutanud Adam Olearius (1603-1671) (Laugaste 1963: 55).

56.Ka kodukäimise lõpetamiseks on kasutatud ligilähedasi vahendeid.

57.Lüüdi karjalased tavatsesid matmast tulles koduteel suvalises paigas korraks maha istuda, öeldes: Mina jätan talle nii pika tee. Aga see, kellel oli tagakahetsetud kallis surnu, tuli oma õueväravasse ja istus sinna (Virtaranta 1964: 207). 
58.Liivlased panid samal põhjusel surnu rinnale punasest lõngast ristikese (Loorits 1927: 43).

59.Lähima sugulase või itkeja kirstul istumine oli tuntud ka karjalastel ja venelastel (Suurhasko 1985: 86). Hantidel oli kombeks, et pärast surnu puusärki panemist istus keegi korraks sellele: kirstu krigin pidi lahkunule teadustama algavast teekonnast (Kulemzin 1984: 136).

60.Naela löömist läbi puusärgi otsalaua surnu jalga on vaadeldud 2. tõrjerühmas.

61.G. Gratshova, viidates teistele autoritele, mainib kummuli matmist neenetsitel, pidades tõenäoliseks selle kohaldamist üksnes shamaanidele või mingil põhjusel kardetud inimestele nende tagasipöördumise vältimiseks (Gratshova 1983: 77).

62.Ühes teates öeldakse: Et surnu enne hauda viimist kodus miskit tempu ei saaks teha, on tarvis teda kummuli keerata (H III 17, 976 (65) < Amb). 